\title{
Systematic Review \\ Effect of Transcranial Direct Current Stimulation Combined with Rehabilitation on Arm and Hand Function in Stroke Patients: A Systematic Review and Meta-Analysis
}

\author{
Joo-Hyun Lee ${ }^{1}\left(\mathbb{D}\right.$, Yu-Jin Jeun ${ }^{2}$, Hae Yean Park ${ }^{3}{ }^{(1)}$ and Young-Jin Jung ${ }^{4, *}$ \\ 1 Department of Occupational Therapy, Baekseok University, Cheonan 31065, Korea; otlove@bu.ac.kr \\ 2 Department of ICT Convergence, The Graduate School, Soonchunhyang University, Asan 31538, Korea; \\ eie0305@naver.com \\ 3 Department of Occupational Therapy, College of Software and Digital Healthcare Convergence, \\ Yonsei University, Wonju 26493, Korea; haepark@yonsei.ac.kr \\ 4 School of Healthcare and Biomedical Engineering, Chonnam National University, Yeosu 59626, Korea \\ * Correspondence: yj@jnu.ac.kr
}

Citation: Lee, J.-H.; Jeun, Y.-J.; Park, H.Y.; Jung, Y.-J. Effect of Transcranial Direct Current Stimulation Combined with Rehabilitation on Arm and Hand Function in Stroke Patients: A Systematic Review and MetaAnalysis. Healthcare 2021, 9, 1705. https://doi.org/10.3390/ healthcare 9121705

\section{Academic Editors:}

Marco Tramontano and Giovanni Galeoto

Received: 8 November 2021 Accepted: 3 December 2021 Published: 8 December 2021

Publisher's Note: MDPI stays neutral with regard to jurisdictional claims in published maps and institutional affiliations.

Copyright: (c) 2021 by the authors. Licensee MDPI, Basel, Switzerland. This article is an open access article distributed under the terms and conditions of the Creative Commons Attribution (CC BY) license (https:/ / creativecommons.org/licenses/by/ $4.0 /)$.

\begin{abstract}
Transcranial direct current stimulation (tDCS) is a noninvasive brain stimulation technique that may enhance motor recovery after stroke. We performed a systematic review and meta-analysis to assess the efficacy of tDCS combined with rehabilitation on arm and hand function after stroke. Electronic databases were searched from their inception to September 2021. We performed a systematic review of selected randomized controlled trials, and methodological qualities were measured using the PEDro (Physiotherapy Evidence Database) scale. We calculated the standardized mean difference for effect size using the Comprehensive Meta-Analysis 3.0 software. We selected 28 studies for the systematic review and 20 studies for the meta-analysis. The overall effect size was 0.480 (95\% CI [0.307; 0.653], $p<0.05)$, indicating a moderate effect size of tDCS combined with rehabilitation for upper extremity function in stroke survivors. The tDCS with occupational therapy/physical therapy $(0.696 ; 95 \%$ CI $[0.390 ; 1.003], p<0.05)$ or virtual reality therapy $(0.510 ; 95 \%$ CI $[0.111 ; 0.909], p<0.05)$ was also significantly more effective than other treatments. This meta-analysis of 20 randomized controlled trials provides further evidence that tDCS combined with rehabilitation, especially occupational therapy/physical therapy and virtual reality therapy, may benefit upper extremity function of the paretic upper limb in stroke patients.
\end{abstract}

Keywords: arm and hand function; meta-analysis; rehabilitation; stroke; systematic review; transcranial direct current stimulation

\section{Introduction}

Non-invasive brain stimulation techniques, such as repetitive transcranial magnetic stimulation (rTMS) and transcranial direct current stimulation (tDCS), have been used in recent years not only to enhance neural plasticity, but also to improve motor function in the context of post-stroke rehabilitation [1]. Although rTMS and tDCS are useful techniques for painless and non-invasive stimulation of the human brain, tDCS is more suitable as a therapeutic tool as it can be applied more easily than rTMS [2]. There are three tDCS methods: (i) anodal tDCS; (ii) cathodal tDCS as unilateral tDCS, which modulates cortical excitability in a polarity-dependent manner at the stimulated primary motor cortex (M1); and (iii) bihemispheric tDCS, which induces both up- and down- regulation of M1 excitability by applying anodal stimulation to M1 in one hemisphere and cathodal stimulation to that in the other hemisphere [3]. Through electrodes applied to the scalp, these stimulation approaches can modulate excitable and inhibitory neuronal networks in both affected and non-affected hemispheres to improve motor function on the paretic side in stroke patients [4]. 
Paralysis of the affected upper extremity interferes with the independent daily life of stroke patients; it induces abnormal muscle tone, weakness, and coordination problems. Recent studies on the application of $\mathrm{tDCS}$ combined with rehabilitation have shown positive results regarding arm and hand recovery in stroke patients. These results indicate that tDCS combined with rehabilitation can maximize the effects of rehabilitation training by removing the imbalance in transcallosal inhibition after subcortical stroke [5]. A study using tDCS in combination with occupational therapy in patients with chronic stroke also demonstrated that fine motor skill deficits can be significantly improved when these interventions are applied simultaneously [6]. However, to date, there have been no metaanalyses providing clearly integrated information regarding the characteristics of tDCS and rehabilitation when applied as a combined intervention. Similarly, no meta-analysis has previously assessed the efficacy of combination therapy for stroke patients.

A systematic review regarding the efficacy of anodal tDCS for upper limb motor recovery reported that anodal tDCS may improve motor function in patients with chronic stroke. Another published systematic review [7], which included 26 studies with 754 participants, compared the effects of active tDCS (anodal, cathodal, or dual), sham tDCS, and physical rehabilitation with respect to the improvement of activities of daily living capacity and arm function. The results indicated that cathodal tDCS applied to the non-lesioned brain area was significantly more effective than other stimulation or rehabilitation techniques in improving the activities of daily living capacity in stroke patients. However, these reviews did not focus on a combination of $\mathrm{tDCS}$ and rehabilitation. In particular, in contrast with cathodal tDCS, the application of anodal tDCS, dual tDCS, and sham tDCS had no significant effects on the activities of daily living capacity in stroke patients [7].

Thus, a systematic investigation of the effectiveness of tDCS combined with rehabilitation is required to clarify its effects on stroke rehabilitation. Meta-analysis is a useful method for quantitatively synthesizing data from clinical trials; it offers greater statistical power, and is more reliable and objective than a single analysis [8].

The purpose of our systematic review was to obtain an overview of the available scientific evidence to determine whether tDCS combined with rehabilitation has any effect on upper extremity function of the paretic side after stroke.

\section{Materials and Methods}

We performed a systematic literature review to analyze the effectiveness of tDCS combined with rehabilitation for upper extremity function recovery in stroke patients.

The inclusion criteria for the studies are as follows: (1) a randomized control trial (RCT) or pilot-RCT study design; (2) a patient population of adults $>18$ years old who had experienced any type of stroke (ischemic or hemorrhage); (3) anodal, cathodal, and dual tDCS combined with therapeutic interventions that were related to rehabilitation such as occupational therapy, physical therapy, robot-assisted therapy, virtual reality therapy, and constraint-induced movement therapy; and (4) outcome measures that were classified as functional ability or recovery of the upper extremity (shoulder, hand, and arm) measured by a validated specific assessment technique, such as the Action Research Arm Test [9] or FuglMeyer Assessment [10]. The experimental group comprised patients who underwent tDCS combined with rehabilitation, and the control group included patients who underwent sham tDCS combined with rehabilitation or those who underwent only rehabilitation.

We searched the following electronic databases for articles published until September 2021: Medline (from 2009), Embase (from 2011), Cochrane register of controlled clinical trials (from 2014), Scopus (from 2006), and other sources (Psychlnfo, Book) for identifying additional records. The search strategies are provided in Appendix A. Our research protocol follows the Preferred Reporting Items for Systematic Reviews and Meta-Analyses guidelines. We registered this analysis in the PROSPERO database (ID: CRD42018109085).

The methodological quality of the selected studies was assessed using the Physiotherapy Evidence Database (PEDro) scale. The PEDro scale was originally developed to measure the methodological quality of clinical trials [11] and consists of 11 items that 
measure the external validity (criterion 1), internal validity (criteria 2-9), and statistical information (criteria 10-11) of a given trial. The range of scores pertaining to internal validity and statistical information is $0-10$, and the following cutoff points are used: 9-10, excellent; 6-8, good; 4-5, fair; and below 4, poor [12].

The effect size and publication bias of the selected studies were analyzed using Comprehensive Meta-Analysis version 3.0 (Biostat; Englewood, NJ, USA). An effect size was defined as the difference between the means of the experimental and control groups after a given intervention was divided by the standard deviation of the control group. We analyzed the mean difference, standardized mean difference, and 95\% confidence interval (CI) to measure effect sizes, which were then used to compare the effects of tDCS combined with other rehabilitations with those of control interventions. The effect sizes of this meta-analysis were reported as small $(\mathrm{d}>0.2)$, moderate $(\mathrm{d}>0.5)$, and large $(\mathrm{d}>0.8)$, as described in a previous study [13]. A positive effect size indicates a better effect with tDCS combined with other rehabilitations compared to rehabilitation alone, while a negative effect size suggests that rehabilitation alone had better effects than combination training.

It is important to assess the extent of heterogeneity among the studies used in a meta-analysis. The extent of heterogeneity can be measured by a heterogeneity test that indicates the variance in each study using Q-statistic and I-squared values. When the Q-value is significant $(p<0.1)$, heterogeneity is present among the studies [14]. The extent of heterogeneity can also be interpreted by I-squared values, ranging from absent (0) to low (25), medium (50), or high (75) [15]. If the effects among studies are significantly heterogeneous, a random-effects model can be used to estimate the overall effect in a metaanalysis. On the other hand, if the effects among studies are significantly homogeneous, a fixed effect model can be used [16].

Publication bias refers to the distortion of the results of a meta-analysis that can occur by including more studies with positive results than those with negative results, because studies with less significant or negative results are less likely to be published [17]. The existence of publication bias was assessed using a funnel plot and Egger's regression. A funnel plot is a graph with the effect size on the $x$-axis and standard error on the $y$-axis. If the pattern of a given funnel plot becomes asymmetrical, with more one-sided results, it means that publication bias is present. The Egger's regression intercept test also detects publication bias by measuring the intercept from regression between the effect size and standard error. When the regression is insignificant $(p>0.05)$, publication bias is considered absent [18].

\section{Results}

We identified 238 articles from four databases (Medline, Embase, Cochrane register of controlled clinical trials, and Scopus) and screened 140 articles after removing duplicate articles. Seventy articles were removed after reviewing the title and abstract. Of the 70 articles selected for full-text review, 42 were excluded because they failed to meet certain inclusion criteria, such as stroke diagnoses, use of combined intervention, or study design (e.g., review articles). Finally, we selected 28 studies for qualitative synthesis, including 20 studies used for quantitative meta-analysis (Figure 1). 


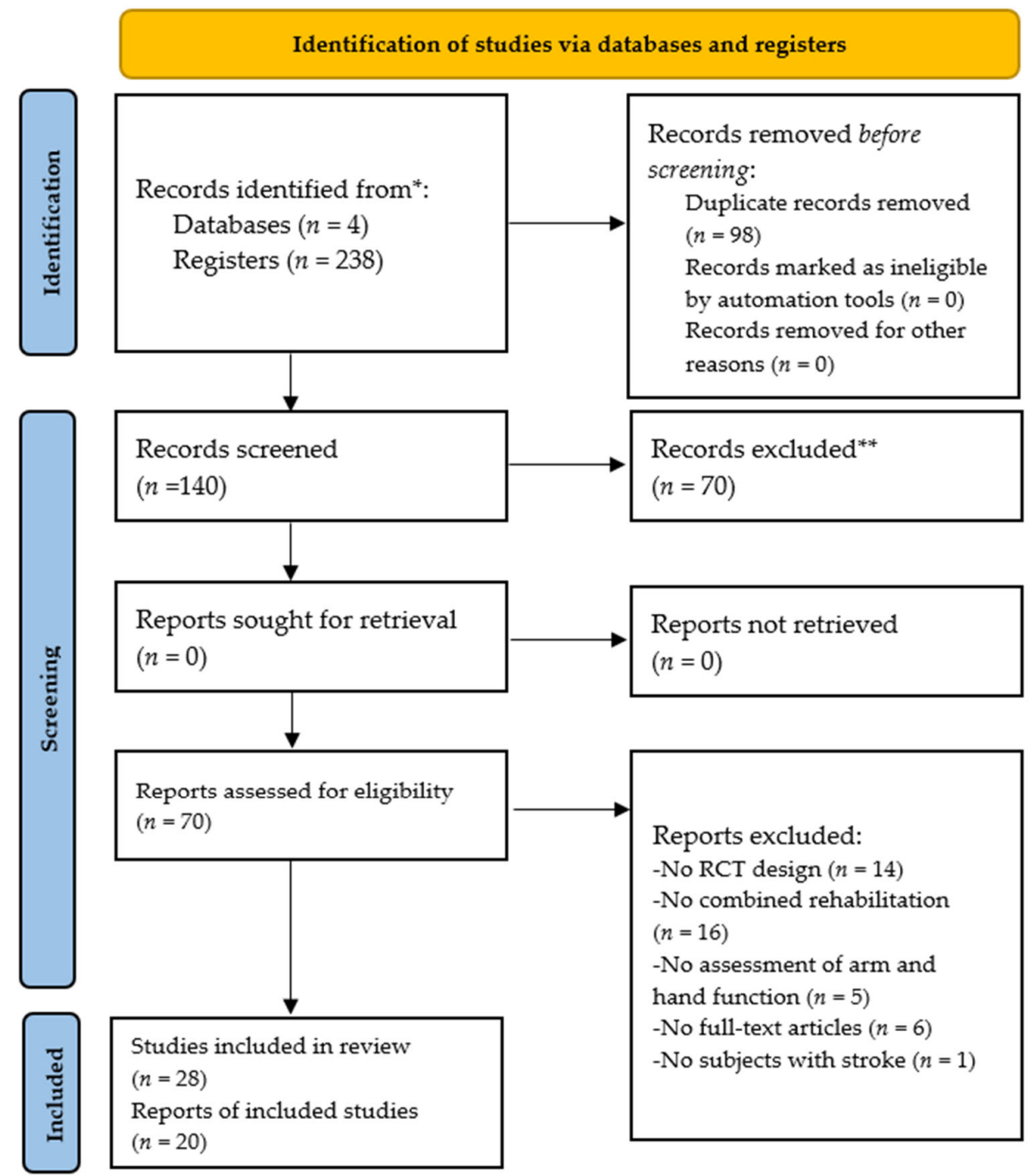

Figure 1. Preferred Reporting Items for Systematic Reviews and Meta-Analyses (PRISMA) 2020 flow diagram of study selection. ${ }^{*}$, record identification; ${ }^{* *}$, record exclusion. RCT, randomized controlled trial.

The total number of patients in the 20 RCTs was 818, including 453 in the experimental group and 365 in the control group (mean age range: $49.3-75.3$ years). The mean time of stroke onset ranged from 5.9 days (acute phase: 0-7 days) to 56.6 months (chronic phase: $>6$ months). The rehabilitation used in combination with tDCS was occupational therapy/physical therapy in eight studies, robot-assisted therapy in six studies, virtual reality therapy in six studies, and constraint-induced movement therapy in three studies. The duration of rehabilitation training varied among the studies from $20 \mathrm{~min}$ to $6 \mathrm{~h}$ per day and from five-day to eight-week periods. The most common analytical tools used to assess upper extremity function or recovery in stroke patients were the upper extremity Fugl-Meyer Test, Wolf Motor Function Test, Box and Block Test, and Action Research Arm Test (Table 1). 
Table 1. Characteristics of studies examining the effects of tDCS combined with other rehabilitation therapies on upper extremity function (cont-).

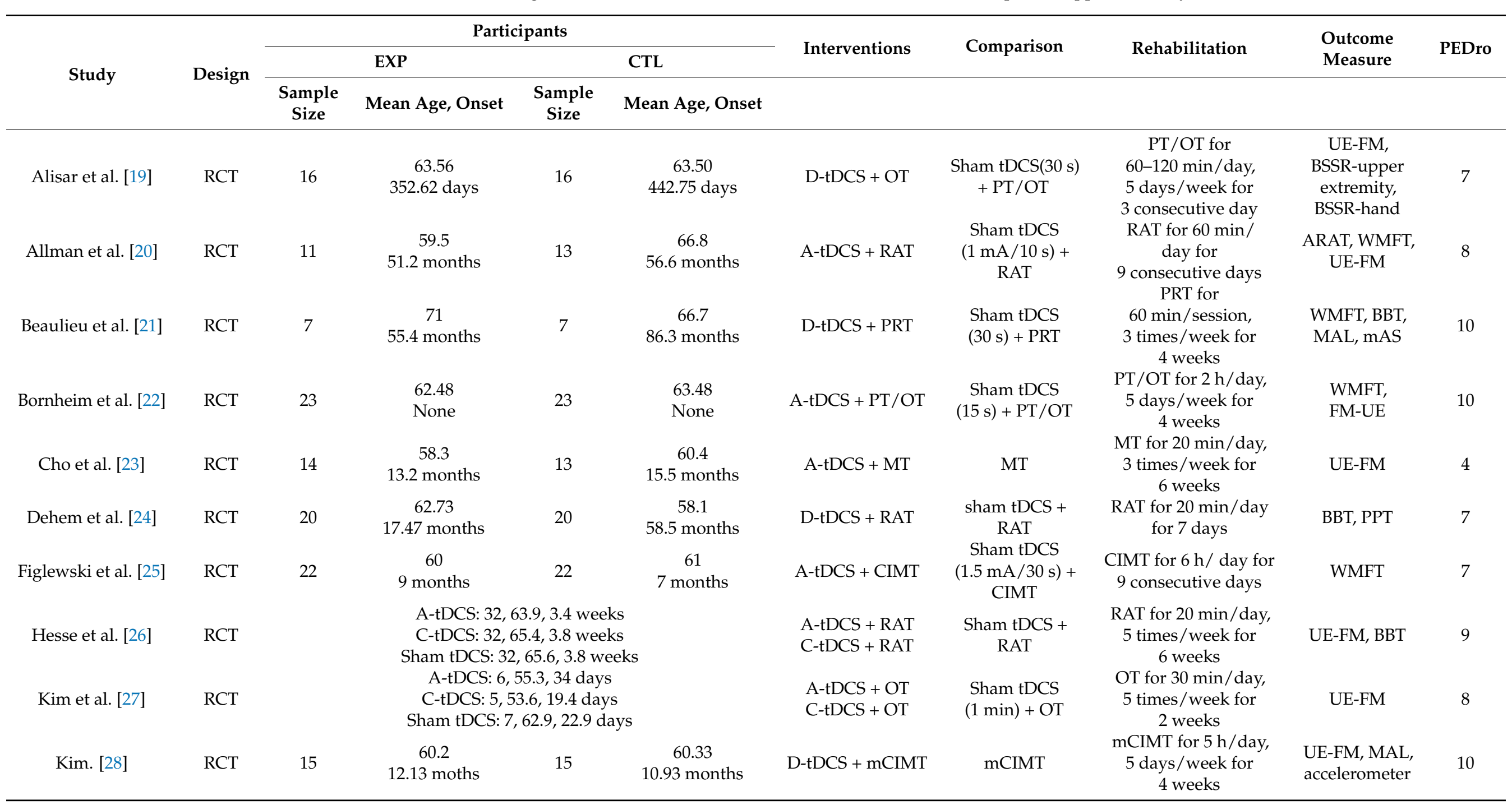


Table 1. Cont

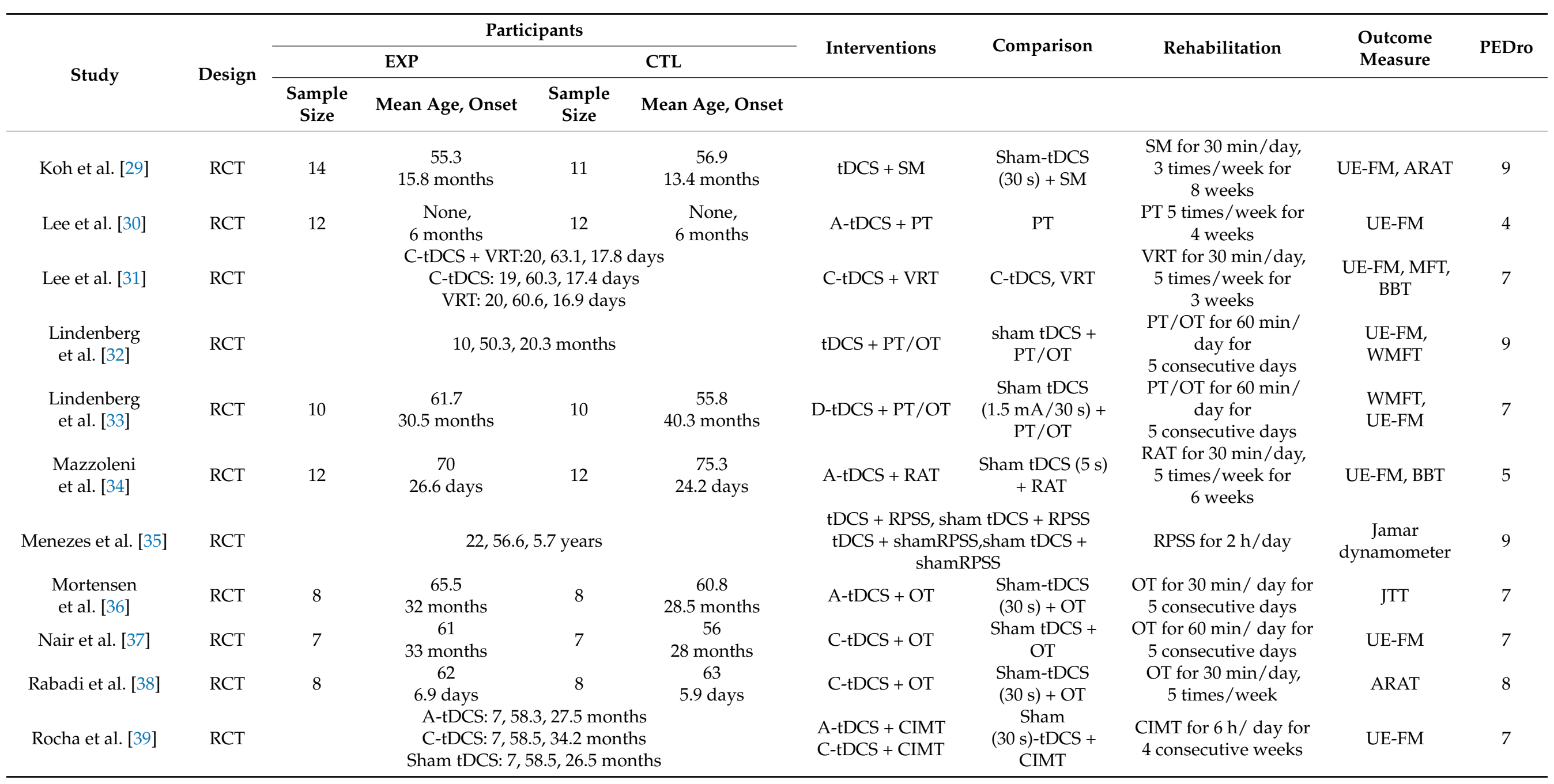


Table 1. Cont.

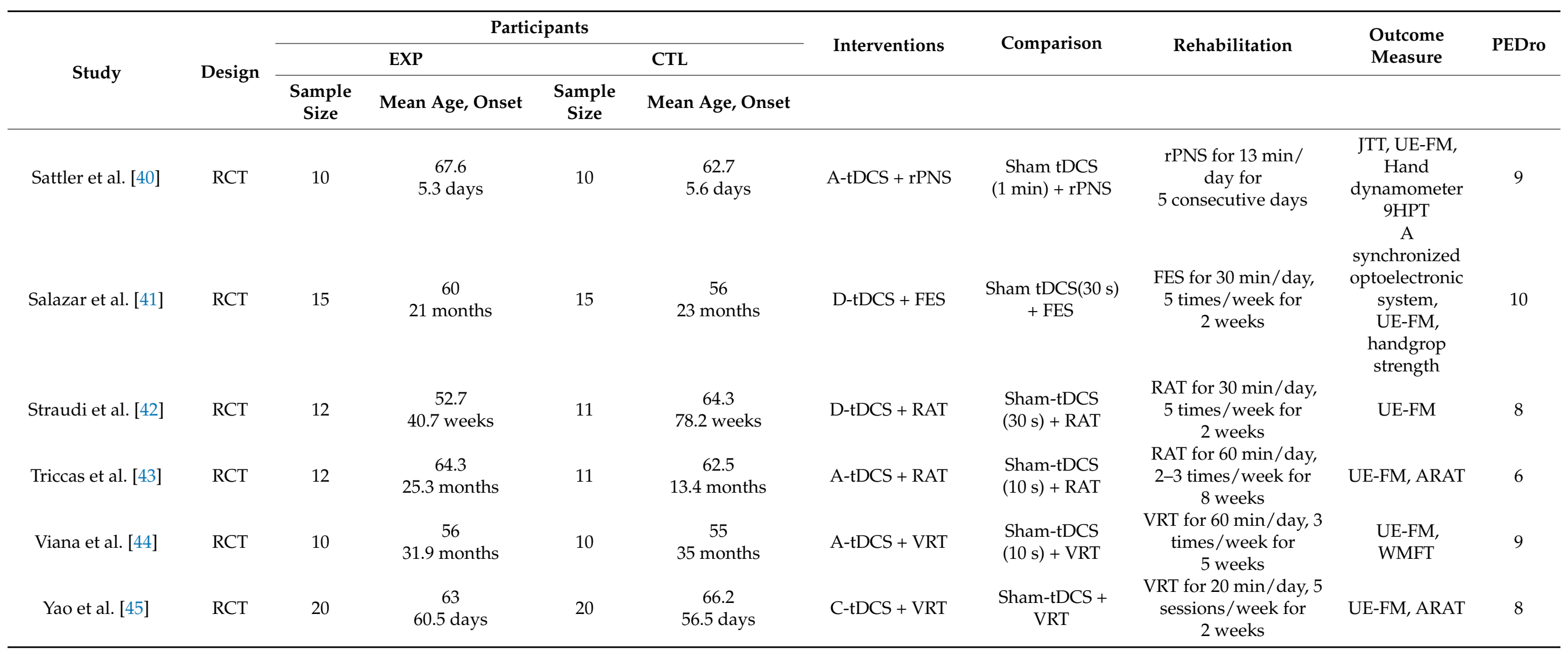

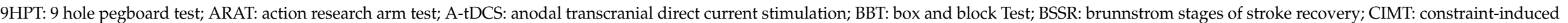

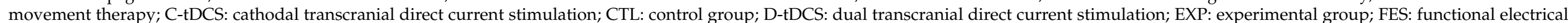

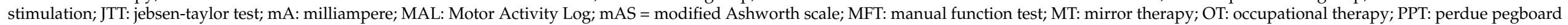

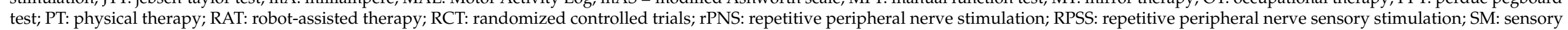

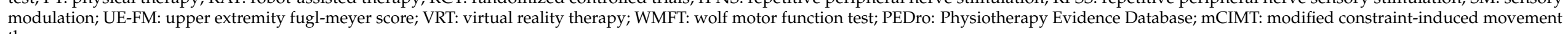
therapy. 
The type of tDCS used was anodal in nine studies, dual in eleven studies, cathodal in three studies, and anodal and cathodal in four studies; one study provided limited information regarding tDCS. Anodal tDCS was applied with the anode placed over the M1 of the affected hemisphere and the cathode over the contralesional supraorbital region. For cathodal tDCS, the cathode was placed over the contralesional motor region, and the anode was placed on the supraorbital region of the affected hemisphere. The average amount of applied current ranged from 1-2 mA (milliampere). A current of $20 \mathrm{~mA}$ was applied only in one study. The delivery duration ranged from 9-30 min (Table 2). The mean (standard deviation) PEDro score across all 28 studies was 7.7 (1.7), with a range from 4 (fair) to 11 (excellent) points. These results indicate that the quality of all reviewed studies was sufficient for the meta-analysis (Table 1).

Table 2. Applied transcranial direct current stimulation (t-DCS) parameters for upper extremity function recovery in patients with stroke.

\begin{tabular}{|c|c|c|c|c|c|}
\hline Study & Site & $\begin{array}{c}\text { Intensity } \\
(\mathrm{mA})\end{array}$ & $\begin{array}{c}\text { Duration } \\
\text { (min.) }\end{array}$ & A/C/D & $\begin{array}{l}\text { Electrode Size } \\
\left(\mathrm{cm}^{2}\right)\end{array}$ \\
\hline Alisar et al. [19] & $\begin{array}{c}\mathrm{A}=\mathrm{C} 3 \text { of the ipsilesional hemisphere } \\
\mathrm{C}=\mathrm{C} 4 \text { of the contralesional hemisphere }\end{array}$ & 2 & 30 & $\mathrm{D}$ & 22 \\
\hline Allman et al. [20] & $\begin{array}{c}\mathrm{A}=\text { primary motor cortex }(\mathrm{M} 1) \text { of the } \\
\text { affected hemisphere } \\
\mathrm{R}=\text { Contralateral supraorbital region }\end{array}$ & 1 & 20 & A & 35 \\
\hline Beaulieu et al. [21] & $\begin{array}{c}\mathrm{A}=\text { Ipsilesional M1 } \\
\mathrm{C}=\text { Contralesionanl M1 }\end{array}$ & 2 & 20 & $\mathrm{D}$ & 35 \\
\hline Bornheim et al. [22] & $\begin{array}{c}\mathrm{A}=\text { MI of the lesioned side } \\
\mathrm{C}=\text { Contralesional eye }\end{array}$ & 1 & 20 & A & 25 \\
\hline Cho et al. [23] & $\begin{array}{c}\mathrm{A}=\mathrm{M} 1 \text { of the affected hemisphere } \\
\mathrm{C}=\text { Contralateral supraorbital region }\end{array}$ & 2 & 20 & A & 35 \\
\hline Dehem et al. [24] & $\begin{array}{l}A=M 1 \text { of the affected hemisphere } \\
C=M 1 \text { of the unaffected hemisphere }\end{array}$ & 1 & 20 & $\mathrm{D}$ & 35 \\
\hline Figlewski et al. [25] & $\begin{array}{l}\mathrm{A}=\mathrm{M} 1 \text { of the affected hemisphere } \\
\mathrm{C}=\mathrm{Contralateral} \text { supraorbital region } \\
\mathrm{A}(\mathrm{A}=\mathrm{M} 1 \text { of the affected hemisphere }\end{array}$ & 1.5 & 30 & A & 35 \\
\hline Hesse et al. [26] & $\begin{array}{l}C=\text { Contralateral supraorbital region }) \\
C(C=M 1 \text { of the unaffected hemisphere } \\
A=\text { Contralateral supraorbital region }) \\
\text { A ( } A=\text { M1 of the affected hemisphere }\end{array}$ & 2 & 20 & $\mathrm{~A} / \mathrm{C}$ & 35 \\
\hline Kim et al. [27] & $\begin{array}{l}\mathrm{C}=\text { Contralateral supraorbital region }) \\
\mathrm{C}(\mathrm{C}=\mathrm{M} 1 \text { of the unaffected emisphere } \\
\mathrm{A}=\text { Contralateral supraorbital region) }\end{array}$ & 2 & 20 & $\mathrm{~A} / \mathrm{C}$ & 25 \\
\hline Kim. [28] & $\begin{array}{l}\mathrm{A}=\mathrm{M} 1 \text { of the affected hemisphere } \\
\mathrm{C}=\mathrm{M} 1 \text { of the unaffected hemisphere }\end{array}$ & 1 & 20 & $\mathrm{D}$ & - \\
\hline Koh et al. [29] & $\begin{array}{l}\mathrm{A}=\mathrm{M} 1 \text { of the affected hemisphere } \\
\mathrm{C}=\mathrm{M} 1 \text { of the unaffected hemisphere }\end{array}$ & 1.5 & 30 & D & 25 \\
\hline Lee et al. [30] & $\begin{array}{c}\mathrm{C}=\text { Non-affected motor region } \\
\mathrm{A}=\text { Contralateral supraorbital region }\end{array}$ & 2 & 20 & C & 25 \\
\hline Lindenberg et al. [32] & $\begin{aligned} \mathrm{A}=\mathrm{M} 1 \text { of the affected hemisphere } \\
\mathrm{C}=\text { Contralateral M1 area }\end{aligned}$ & 1.5 & 30 & $\mathrm{D}$ & - \\
\hline Lindenberg et al. [33] & $\begin{array}{c}\mathrm{A}=\mathrm{M} 1 \text { of the affected hemisphere } \\
\mathrm{C}=\text { Contralateral M1 area } \\
\mathrm{A}=\text { Presumed hand area of affected }\end{array}$ & 1.5 & 30 & D & 16.3 \\
\hline Mazzoleni et al. [34] & $\begin{array}{c}\text { hemisphere } \\
\mathrm{C}=\text { Contralateral orbit region }\end{array}$ & 2 & 20 & $\mathrm{D}$ & 35 \\
\hline Menezes et al. [35] & $\begin{array}{c}\mathrm{A}=\mathrm{M} 1 \text { of the affected hemisphere } \\
\mathrm{C}=\text { Contralateral supraorbital region }\end{array}$ & 1 & 20 & A & - \\
\hline Mortensen et al. [36] & $\begin{array}{c}\mathrm{A}=\mathrm{M} 1 \text { of the affected hemisphere } \\
\mathrm{C}=\text { Contralateral supraorbital region }\end{array}$ & 1.5 & 20 & A & 35 \\
\hline Nair et al. [37] & $\begin{array}{c}\mathrm{C}=\text { Non-affected motor region } \\
\mathrm{R}=\text { Contralateral supraorbital region }\end{array}$ & 1 & 30 & C & - \\
\hline
\end{tabular}


Table 2. Cont.

\begin{tabular}{|c|c|c|c|c|c|}
\hline Study & Site & $\begin{array}{l}\text { Intensity } \\
(\mathrm{mA})\end{array}$ & $\begin{array}{l}\text { Duration } \\
\text { (min.) }\end{array}$ & $\mathrm{A} / \mathrm{C} / \mathrm{D}$ & $\begin{array}{l}\text { Electrode Size } \\
\left(\mathrm{cm}^{2}\right)\end{array}$ \\
\hline Rabadi et al. [38] & $\begin{array}{c}\text { A }(\mathrm{A}=\mathrm{M} 1 \text { of the affected hemisphere } \\
\mathrm{C}=\text { Contralateral supraorbital region }) \\
\mathrm{C}(\mathrm{C}=\mathrm{M} 1 \text { of the unaffected hemisphere } \\
\mathrm{A}=\text { Contralateral supraorbital region })\end{array}$ & 1 & 30 & $\mathrm{~A} / \mathrm{C}$ & 35 \\
\hline Rocha et al. [39] & $\begin{array}{c}\mathrm{A}(\mathrm{A}=\mathrm{M} 1 \text { of the affected hemisphere } \\
\mathrm{C}=\text { Contralateral supraorbital region }) \\
\mathrm{C}(\mathrm{C}=\mathrm{M} 1 \text { of the unaffected hemisphere } \\
\mathrm{A}=\text { Contralateral supraorbital region })\end{array}$ & 1 & $\begin{array}{l}A=13 \\
C=9\end{array}$ & $\mathrm{~A} / \mathrm{C}$ & 35 \\
\hline Salazar et al. [41] & $\begin{array}{c}\mathrm{A}=\text { Ipsilesional M1 } \\
\mathrm{C}=\text { Contralesionanl M1 }\end{array}$ & 2 & 30 & $\mathrm{D}$ & 25 \\
\hline Sattler et al. [40] & $\begin{array}{c}\mathrm{A}=\mathrm{M} 1 \text { of the affected hemisphere } \\
\mathrm{C}=\text { Contralateral supraorbital region }\end{array}$ & 1.2 & 13 & A & 35 \\
\hline Shaheiwola et al. [46] & $\begin{array}{l}\mathrm{A}=\mathrm{M} 1 \text { of the affected hemisphere } \\
\mathrm{C}=\mathrm{M} 1 \text { of the unaffected hemisphere }\end{array}$ & 2 & 20 & $\mathrm{D}$ & 25 \\
\hline Straudi et al. [42] & $\begin{array}{c}\mathrm{A}=\mathrm{M} 1 \text { of the affected hemisphere } \\
\mathrm{C}=\text { Contralateral } \mathrm{M} 1 \text { area }\end{array}$ & 1 & 30 & $\mathrm{D}$ & 35 \\
\hline Triccas et al. [43] & $\begin{array}{c}\mathrm{A}=\mathrm{M} 1 \text { of the affected hemisphere } \\
\mathrm{C}=\text { Contralateral supraorbital region }\end{array}$ & 1 & 20 & A & 20 \\
\hline Viana et al. [44] & $\begin{array}{c}\mathrm{A}=\mathrm{M} 1 \text { of the affected hemisphere } \\
\mathrm{C}=\text { Contralateral orbit }\end{array}$ & 20 & 13 & A & 35 \\
\hline Yao et al. [45] & $\begin{array}{l}\mathrm{C}=\mathrm{M} 1 \text { of the unaffected hemisphere } \\
\mathrm{R}=\mathrm{Contralateral} \mathrm{supraorbital} \mathrm{region}\end{array}$ & 2 & 20 & $\mathrm{C}$ & 35 \\
\hline
\end{tabular}

A: anodal transcranial direct current stimulation, C: cathodal transcranial direct current stimulation, D: dual transcranial direct current stimulation, $\mathrm{mA}$ : milliampere.

In this meta-analysis, we examined 20 studies comparing the effects of tDCS combined with rehabilitation to those of sham tDCS with rehabilitation or rehabilitation only in stroke patients. Table 3 presents the effect size, overall Q-squared, and I-squared values. The overall effect size for the effectiveness of tDCS combined with rehabilitation was $0.480(95 \%$ CI $[0.307,0.653], p<0.05)$, which indicates that the combination of tDCS and rehabilitation had a higher value than sham tDCS with rehabilitation or rehabilitation only [13]. We used a fixed effect model to assess the variation within and between studies because the $p$-value of the Q-value was greater than 0.05 in the heterogeneity test, and the I-squared value of 0.000 suggested the absence of heterogeneity (Table 3 ).

Table 3. Effect size of tDCS combined with rehabilitation.

\begin{tabular}{|c|c|c|c|c|c|c|c|c|}
\hline \multirow{2}{*}{ Category } & \multirow{2}{*}{$\begin{array}{c}\text { Number of } \\
\text { Studies }\end{array}$} & \multicolumn{3}{|c|}{ Effect Size } & \multicolumn{4}{|c|}{ Heterogeneity } \\
\hline & & d & $\mathbf{Z}$ & $p<$ & Q Value & df $(Q)$ & $p$ & $\mathrm{I}^{2}$ \\
\hline \multicolumn{9}{|c|}{ Random effects analysis } \\
\hline $\begin{array}{l}\text { Constraint-induced } \\
\text { movement therapy }\end{array}$ & 3 & 0.516 & 1.245 & 0.213 & 6.297 & 2 & 0.043 & 68.241 \\
\hline Robot-assisted therapy & 6 & 0.256 & 1.674 & 0.094 & 1.475 & 5 & 0.916 & 0.000 \\
\hline $\begin{array}{l}\text { Occupational } \\
\text { therapy/physical therapy }\end{array}$ & 8 & 0.699 & 4.364 & 0.000 & 7.297 & 7 & 0.399 & 4.064 \\
\hline Virtual reality therapy & 3 & 0.510 & 2.506 & 0.012 & 0.659 & 2 & 0.719 & 0.000 \\
\hline Overall & 20 & 0.483 & 5.340 & 0.000 & 19.793 & 19 & 0.407 & 4.009 \\
\hline
\end{tabular}

tDCS: transcranial direct current stimulation.

In total, eight studies were included in the occupational/physical therapy group. The effect size of tDCS combined with occupational therapy/physical therapy for stroke patients was $0.696(95 \% \mathrm{CI}[0.390,1.003], p<0.05)$, which is interpreted as a medium effect size. Three studies were included in the virtual reality therapy group, and the effect size of tDCS combined with virtual reality therapy was 0.510 (95\% CI [0.111, 0.909], $p<0.05$ ), 
which is interpreted as a medium effect size. Next, three studies were included in the constraint-induced movement therapy group. The effect size of tDCS combined with CIMT was $0.479(95 \% \mathrm{CI}[0.047,0.910], p<0.05)$, which is interpreted as close to the median effect size. The remaining six studies were included in the robot-assisted therapy group, and the effect size of tDCS combined with robot-assisted therapy was 0.256 (95\% CI [-0.044, 0.557], $p>0.05$ ), which is interpreted as a small effect size (Figure 2).

Mbdel Studyname

\begin{tabular}{lrrrrrrrr} 
& $\begin{array}{c}\text { Std diff } \\
\text { in means }\end{array}$ & $\begin{array}{c}\text { Standard } \\
\text { enror }\end{array}$ & Variance & $\begin{array}{c}\text { Lower } \\
\text { limit }\end{array}$ & $\begin{array}{c}\text { Upper } \\
\text { limit }\end{array}$ & ZValue & p-Value \\
Rocha et al. (2016) & 0.056 & 0.535 & 0.286 & -0.991 & 1.104 & 0.105 & 0.916 \\
Figlewski et al. (2017) & 0.139 & 0.302 & 0.091 & -0.453 & 0.731 & 0.460 & 0.645 \\
\multicolumn{1}{l}{ Kim(2021) } & 1.325 & 0.403 & 0.163 & 0.535 & 2.116 & 3.286 & 0.001 \\
Fixed & 0.479 & 0.220 & 0.048 & 0.047 & 0.910 & 2.174 & 0.030 \\
Random & 0.516 & 0.415 & 0.172 & -0.297 & 1.329 & 1.245 & 0.213
\end{tabular}

$\underline{\text { Model Sturkmme }}$

Nair et al (2011)
Lee et al (2015)
Lindenberg et al (2010)
Shaherivola et al (2018)
Rabadi et al (2017)
$\quad$ Cho et al (2015)
Alisar et al (2019)
$\quad$ Beaulieu et al (2018)
Fxed
Random

(A) $\underline{\text { Statistics for each sturv }}$

\begin{tabular}{|c|c|c|c|c|c|c|}
\hline $\begin{array}{l}\text { Stddfff } \\
\text { inmears }\end{array}$ & $\begin{array}{c}\text { Staurhrd } \\
\text { error }\end{array}$ & Variance & $\begin{array}{c}\text { Lower } \\
\text { limit }\end{array}$ & $\begin{array}{c}\text { Uper } \\
\text { limit }\end{array}$ & ZValue & p-Vahue \\
\hline 0.307 & 0.538 & 0.289 & -0.747 & 1.361 & 0.571 & 0.568 \\
\hline 1.128 & 0.440 & 0.193 & 0.267 & 1.990 & 2.567 & 0.010 \\
\hline 0.232 & 0.449 & 0.201 & -0.647 & 1.112 & 0.518 & 0.605 \\
\hline 0.284 & 0.367 & 0.135 & -0.435 & 1.004 & 0.775 & 0.438 \\
\hline 1.003 & 0.530 & 0.281 & -0.037 & 2.042 & 1.890 & 0.059 \\
\hline 1.241 & 0.421 & 0.177 & 0.416 & 2.065 & 2.950 & 0.003 \\
\hline 0.500 & 0.359 & 0.129 & -0.204 & 1.204 & 1.393 & 0.164 \\
\hline 1.335 & 0.591 & 0.349 & 0.177 & 2.494 & 2.259 & 0.024 \\
\hline 0.696 & 0.156 & 0.024 & 0.390 & 1.003 & 4.451 & 0.000 \\
\hline .699 & 0.160 & 0.026 & 0.385 & 1.013 & 4.364 & 0.000 \\
\hline
\end{tabular}

(B)

$\underline{\text { Nodel }}$ Studyname
Statistics for each study

$\begin{array}{rcrcccc}\begin{array}{c}\text { Stddiff } \\ \text { in means }\end{array} & \begin{array}{c}\text { Standard } \\ \text { e1ror }\end{array} & \text { Variance } & \begin{array}{c}\text { Lower } \\ \text { limit }\end{array} & \begin{array}{c}\text { Upper } \\ \text { limit }\end{array} & \text { ZValue } & \text { p-Value } \\ 0.174 & 0.409 & 0.167 & -0.628 & 0.976 & 0.426 & 0.670 \\ 0.271 & 0.322 & 0.104 & -0.360 & 0.901 & 0.841 & 0.400 \\ 0.261 & 0.419 & 0.176 & -0.561 & 1.082 & 0.622 & 0.534 \\ 0.326 & 0.412 & 0.170 & -0.482 & 1.134 & 0.790 & 0.429 \\ 0.660 & 0.429 & 0.184 & -0.180 & 1.500 & 1.540 & 0.124 \\ 0.029 & 0.316 & 0.100 & -0.591 & 0.649 & 0.091 & 0.927 \\ 0.256 & 0.153 & 0.023 & -0.044 & 0.557 & 1.674 & 0.094 \\ 0.256 & 0.153 & 0.023 & -0.044 & 0.557 & 1.674 & 0.094\end{array}$

Stddiff in means and $95 \% \mathrm{CI}$

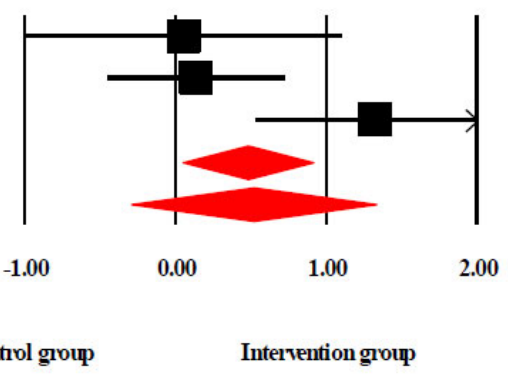

Control group
Stdd diff in mears ard $95 \%$ CI

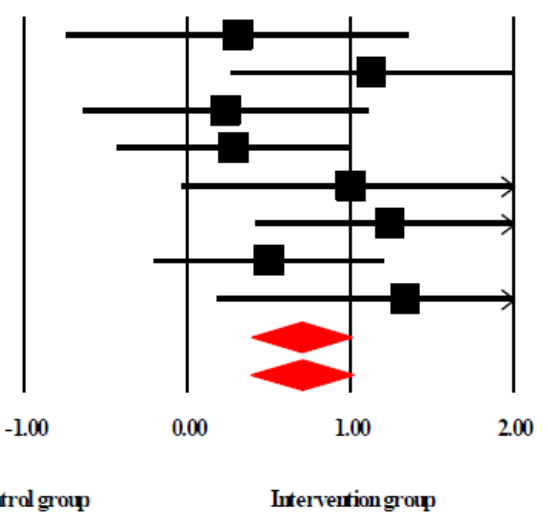

Std diff in means and $95 \% \mathrm{CI}$

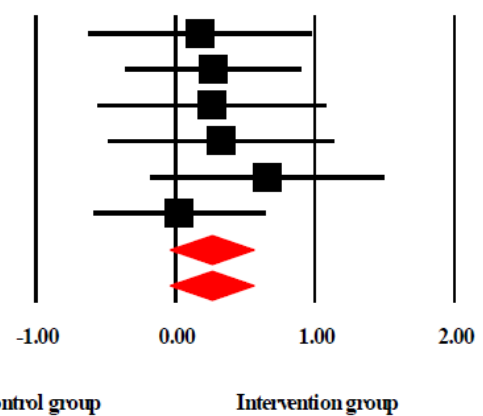

(C)

Figure 2. Cont. 


\begin{tabular}{|c|c|c|c|c|c|c|c|c|}
\hline \multirow[t]{2}{*}{ Model } & \multirow[t]{2}{*}{$\underline{\text { Stuclyname }}$} & \multirow[b]{2}{*}{$\begin{array}{l}\text { Stddiff } \\
\text { in means }\end{array}$} & \multirow[b]{2}{*}{$\begin{array}{l}\text { Standard } \\
\text { enror }\end{array}$} & \multicolumn{3}{|c|}{ Statistics for each study } & \multirow[b]{2}{*}{ ZValue } & \multirow[b]{2}{*}{ p-Value } \\
\hline & & & & Variance & $\begin{array}{l}\text { Lower } \\
\text { limit }\end{array}$ & $\begin{array}{c}\text { Upper } \\
\text { limit }\end{array}$ & & \\
\hline & Viana et al.(2014) & 0.496 & 0.454 & 0.206 & -0.394 & 1.386 & 1.093 & 0.275 \\
\hline & Lee et al. (2014) & 0.703 & 0.326 & 0.106 & 0.064 & 1.341 & 2.157 & 0.031 \\
\hline & Yao et al. (2020) & 0.333 & 0.318 & 0.101 & -0.291 & 0.957 & 1.046 & 0.295 \\
\hline Fixed & & 0.510 & 0.204 & 0.041 & 0.111 & 0.909 & 2.506 & 0.012 \\
\hline Random & & 0.510 & 0.204 & 0.041 & 0.111 & 0.909 & 2.506 & 0.012 \\
\hline
\end{tabular}

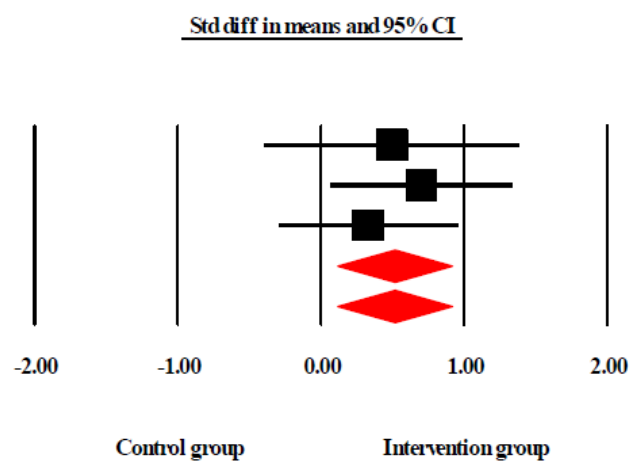

(D)

Figure 2. Forest plot showing the effect sizes for transcranial direct current stimulation combined with rehabilitation in stroke patients. (A) Constraint-induced movement therapy. (B) Occupational therapy/physical therapy. (C) Robot therapy. (D) Virtual reality therapy. Std diff: standard difference.

Funnel plots of effect size against precision were used to investigate the presence of publication bias. The funnel plot was symmetrical across the center of the mean vertical axes of the funnel plot (Figure 3).

Funnel Plot of Standard Error by Std diff in means

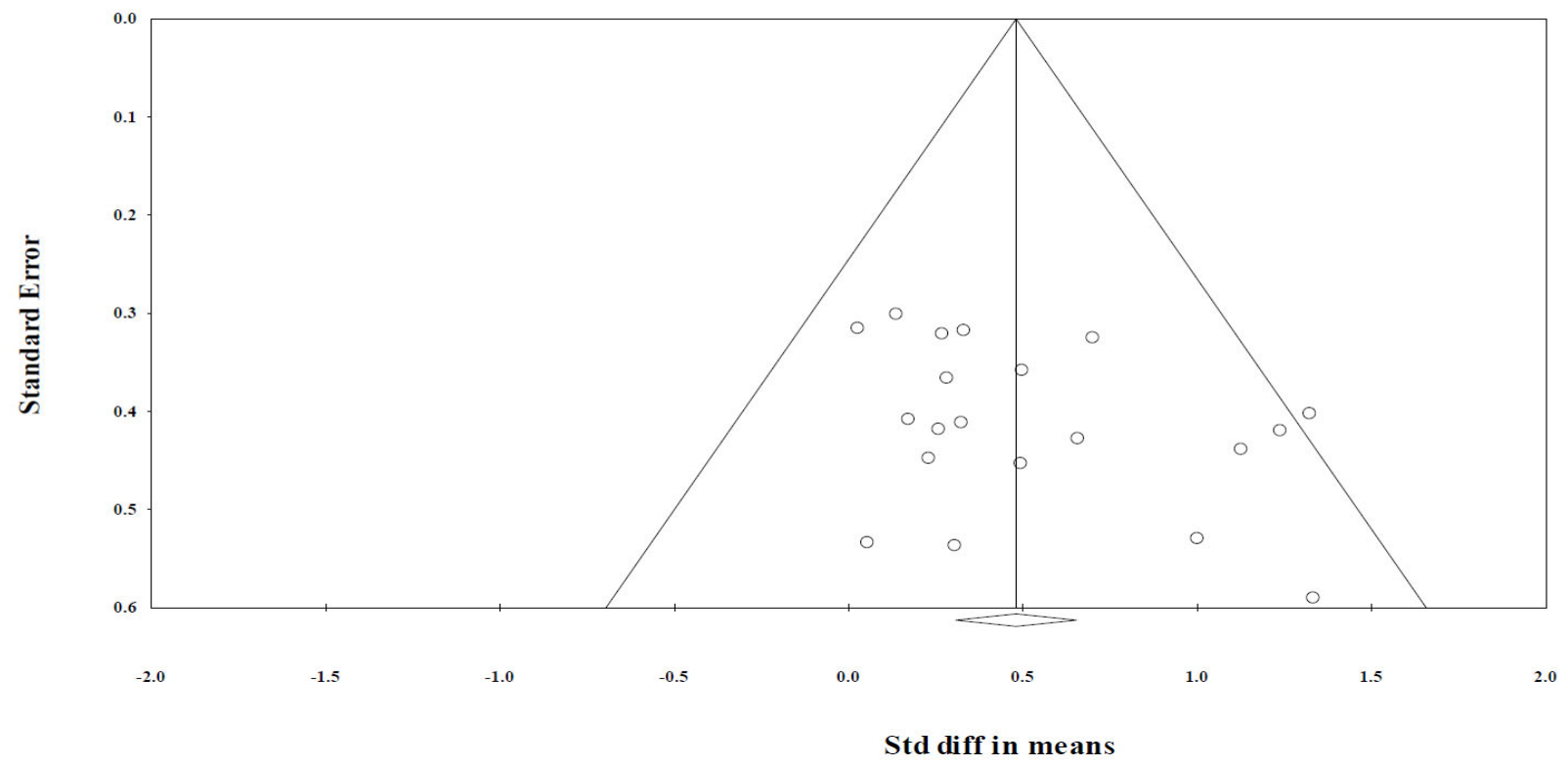

Figure 3. Funnel plot for publication bias. Std diff: standard difference.

\section{Discussion}

We aimed to compare the efficacy of tDCS with rehabilitation and that of sham tDCS with rehabilitation or rehabilitation alone using a systematic review and meta-analysis. This systematic review included 28 randomized controlled trials with 818 stroke patients who underwent occupational therapy/physical therapy, robot-assisted therapy, virtual reality therapy, and constraint-induced movement therapy. The upper extremity FuglMeyer Test, Wolf Motor Function Test, Box and Block Test, and Action Research Arm Test were used for the measurement of upper arm and hand movement function.

The analytic results of the 20 articles included in the meta-analysis revealed a significant overall effect size of tDCS combined with rehabilitation. Although conflicting results were found in a previous network meta-analysis, in that stroke patients showed no significant improvement in arm function with only tDCS [7], our findings suggest that tDCS 
combined with rehabilitation was more effective for upper extremity function recovery in stroke patients than sham tDCS with rehabilitation or rehabilitation only. Notably, our findings corroborate the findings of another meta-analysis published previously [47]. One possible reason for these findings is use-dependent plasticity changes, which occur in a multiregional brain network when non-invasive brain stimulation is applied in combination with rehabilitation [48]. In other words, the effectiveness of upper extremity rehabilitation can be increased substantially when used together with non-invasive brain stimulation. However, further studies are required to assess the difference in effect according to the degree of damage and onset of stroke.

Among the four types of rehabilitation, the effect size of tDCS in combination with occupational therapy/physical therapy or virtual reality therapy was greater than that of robot-assisted therapy or constraint-induced movement therapy in stroke patients. The occupational therapy/physical therapy used in eight studies was administered by trained therapists, and included proprioceptive neuromuscular facilitative approaches, functional motor tasks, goal-directed activities, mirror therapy, and task-oriented movements with functional electrical stimulation $[23,30,33,37,38,46]$. The virtual reality therapy used in three studies were therapeutic approaches that allowed patients to interact with tools such as computer games, programs for motor training, and virtual and robotic systems, thereby minimizing assistance from therapists [20,31,34,42-44]. Furthermore, the constraint-induced movement therapy used in three studies was administered to patients during their daily activities, and they were provided instructions regarding proper technique by the therapists $[25,39]$.

The results of this meta-analysis suggest that tDCS combined with interventions provided by therapists had a greater effect on upper extremity function in stroke patients than interventions provided primarily by equipment, highlighting the important role of therapists in rehabilitation. These results have great implications in terms of the clinical application of $\mathrm{tDCS}$ combined with rehabilitation. tDCS in combination with occupational therapy/physical therapy or virtual reality therapy had a larger effect size than with robot-assisted therapy or constraint-induced movement therapy; however, this does not mean that tDCS in combination with robot-assisted therapy or constraint-induced movement therapy should not be considered. The reason is that the period and frequency of the four types of rehabilitation applied together with tDCS as well as the fact that the patient conditions were different should be considered. Thus, each clinician should select applicable rehabilitation treatments along with their own treatment environment and tDCS by referring to the results of this study in the rehabilitation setting. Moreover, they need to consider several factors before administering rehabilitation treatments. The efficacy of equipment systems for robot-assisted therapy may be somewhat influenced by the lack of computer skills of some therapists or the lack of interaction between therapists and patients [49]. Additionally, most occupational therapy/physical therapy involves performing tasks based on activities of daily living at home rather than in a clinical context. Therefore, it is important to actively provide interventions using daily living tasks for stroke patients by relying on caregivers, therapists, or the patients themselves in a home-like setting, rather than in simulations.

The funnel plot of effect size to identify publication bias in the 20 selected studies had a symmetrical funnel shape centering around the mean effect size plot, and the Egger's regression intercept had a $p$-value lesser than 0.05 . Thus, the studies selected for this meta-analysis had no significant publication bias [50].

Our meta-analysis had some limitations. First, the control group in our study included patients who underwent sham tDCS, solely tDCS, or rehabilitation. This negatively affects the interpretability of the results, and placebo effects of real tDCS cannot be excluded. Future studies should focus on comparisons with a control group receiving sham tDCS. Second, we focused on effective interventions combined with tDCS. It is necessary to include different outcome measures such as the characteristics of stroke patients, types of applied tDCS, and attachment area of the electrodes during tDCS. Third, constraint-induced 
movement therapy and virtual reality therapy were used in fewer studies compared with other rehabilitation types; this may have influenced the effect size of the meta-analysis.

\section{Conclusions}

Despite the abovementioned limitations, this meta-analysis suggests that tDCS combined with rehabilitation can improve upper extremity function in stroke patients. In particular, tDCS combined with occupational therapy/physical therapy had a significantly greater effect on upper extremity function recovery in stroke survivors with hemiplegia. These results suggest clinicians to consider using tDCS as a compliment to the rehabilitation techniques provided in their clinical settings.

Author Contributions: Conceptualization, J.-H.L., Y.-J.J. (Yu-Jin Jeun) and H.Y.P.; data curation, J.-H.L. and Y.-J.J. (Yu-Jin Jeun); formal analysis, J.-H.L. and Y.-J.J. (Yu-Jin Jeun ); funding acquisition, J.-H.L.; methodology, Y.-J.J. (Young-Jin Jung); project administration, Y.-J.J. (Young-Jin Jung); supervision, Y.-J.J. (Young-Jin Jung); writing—original draft, J.-H.L., Y.-J.J. (Yu-Jin Jeun), and H.Y.P.; writing-review and editing, J.-H.L., Y.-J.J. (Yu-Jin Jeun), H.Y.P. and Y.-J.J. (Young-Jin Jung). All authors have read and agreed to the published version of the manuscript.

Funding: This research was funded by the National Research Foundation of Korea (NRF) via a grant funded by the South Korean government (MSIT), grant number 2019R1F1A1060309 \& 2021M3A9E4081266 (Bio \& Medical Technology Development Program).

Institutional Review Board Statement: Not applicable.

Informed Consent Statement: Not applicable.

Data Availability Statement: Not applicable.

Conflicts of Interest: The authors declare no conflict of interest.

\section{Appendix A}

1. Search strategy for Pubmed:

\#1 "random*" [Text Word] OR (("Random Allocation"[Mesh]) OR "Randomized

Controlled Trial" [Publication Type]) OR "Randomized Controlled Trials as Topic"[Mesh] \#2 animals NOT humans

\#3 \#1 NOT \#2

\#4 stroke[tiab] OR "Cerebrovascular Accident" [tiab] OR "Cerebrovascular Accidents"

[tiab] OR strokes[tiab] OR Hemiparesis[tiab] OR Hemipareses[tiab] \#5 (((“'Stroke"[Mesh]) OR “Cerebrovascular accident"[Mesh]) OR “Brain Ischemia”[Mesh])

OR “Cerebral Infarction"[Mesh]) OR “Intracranial Hemorrhages”[Mesh] \#6 \#4 OR \#5 \#5 (“Transcranial Direct Current Stimulation"[Mesh]) OR tDCS [Text Word] OR Cathodal [Text Word] OR Anodal [Text Word] \#6 (((("Physical Therapy Modalities"[Mesh]) OR “Exercise Therapy"[Mesh]) OR “Rehabilitation"[Mesh]) OR "Recovery of Function"[Mesh]) OR "Physical Stimulation" [Mesh] \#7 \#5 AND \#6 \#8 (((((upper-limb[tiab]) OR upper-extremity[tiab]) OR upper limb[tiab]) OR upper extremity[tiab]) OR hand[tiab]) OR arm[tiab] \#9 \#3 AND \#6 AND \#7 AND \#8.

2. Search strategy for cochrane controlled register of trials: \#1 stroke or "Cerebrovascular Accident" or "Cerebrovascular Accidents" or strokes or

Hemiparesis or Hemipareses: ti, ab, kw \#2 MeSH descriptor: [Stroke] explode all trees \#3 MeSH descriptor: [Brain Ischemia] explode all trees \#4 MeSH descriptor: [Cerebral Infarction] explode all trees \#5 MeSH descriptor: [Intracranial Hemorrhages] explode all trees \#6 \#1 or \#2 or \#3 or \#4 or \#5 
\#7 MeSH descriptor: [Transcranial Direct Current Stimulation] explode all trees \#8 MeSH descriptor: [Physical Therapy Modalities] explode all trees

\#9 MeSH descriptor: [Exercise Therapy] explode all trees

\#10 MeSH descriptor: [Rehabilitation] explode all trees

\#11 MeSH descriptor: [Recovery of Function] explode all trees

\#12 MeSH descriptor: [Physical Stimulation] explode all trees

$\# 13 \# 8$ or \#9 or \#10 or \#11 or \#12

$\# 14 \# 7$ and \#13

\#15 (upper-limb or upper-extremity or"upper limb" or "upper extremity" or hand or arm): ti,ab,kw

$\# 16$ \#6 and \#14 and \#15.

3. Search strategy for EMBASE:

\#1 'random '”: ab,ti OR 'randomized controlled trial':ab,ti OR 'randomized controlled trial (topic)':ab,ti OR 'random allocation':ab,ti

\#2 'stroke':ab,ti OR 'cerebrovascular accident':ab,ti OR 'cerebrovascular accidents':ab,ti

OR 'strokes':ab,ti OR ‘hemiparesis':ab,ti OR 'hemipareses':ab,ti

\#3 'transcranial direct curent stimulation':ab,ti OR 'tdcs':ab,ti OR 'cathodal':ab,ti OR 'anodal':ab,ti

\#4 'physical therapy modalities':ab,ti OR 'exercise therapy':ab,ti OR 'rehabilitation':ab,ti OR 'recovery of function': ab,ti OR 'physical stimulation':ab,ti

\#5 'upper-limb':ab,ti OR 'upper-extremity':ab,ti OR 'upper limb':ab,ti OR 'upper extremity':ab,ti OR 'hand':ab,ti OR 'arm':ab,ti \#6 \#1 AND \#2 AND \#3 AND \#4 AND \#5

4. Search strategy for SCOPUS:

\#1 TITLE-ABS-KEY ("random*" OR "Random Allocation" OR “Randomized Controlled Trial" OR "Randomized Controlled Trials as Topic")

\#2 TITLE-ABS-KEY (stroke OR “Cerebrovascular Accident" OR "Cerebrovascular Accidents" OR strokes OR hemiparesis OR hemipareses)

\#3 TITLE-ABS-KEY ("Transcranial Direct Current Stimulation" OR tdcs OR cathodal OR anodal)

\#4 TITLE-ABS-KEY ("Physical Therapy Modalities" OR “Exercise Therapy" OR “Rehabilitation" OR "Recovery of Function" OR "Physical Stimulation")

\#5 TITLE-ABS-KEY (upper-limb OR upper-extremity OR "upper limb" OR “upper extremity" OR hand OR arm).

\section{References}

1. Grefkes, C.; Fink, G.R. Noninvasive brain stimulation after stroke: It is time for large randomized controlled trials! Curr. Opin. Neurol. 2016, 29, 714-720. [CrossRef]

2. Priori, A.; Hallett, M.; Rothwell, J.C. Repetitive transcranial magnetic stimulation or transcranial direct current stimulation? Brain Stimul. 2009, 2, 241-245. [CrossRef] [PubMed]

3. Naros, G.; Geyer, M.; Koch, S.; Mayr, L.; Ellinger, T.; Grimm, F.; Gharabaghi, A. Enhanced motor learning with bilateral transcranial direct current stimulation: Impact of polarity or current flow direction? Clin. Neurophysiol. 2016, 127, 2119-2126. [CrossRef] [PubMed]

4. Jackson, M.P.; Rahman, A.; Lafon, B.; Kronberg, G.; Ling, D.; Parra, L.C.; Bikson, M. Animal models of transcranial direct current stimulation: Methods and mechanisms. Clin. Neurophysiol. 2016, 127, 3425-3454. [CrossRef]

5. Schjetnan, A.G.P.; Faraji, J.; Metz, G.A.; Tatsuno, M.; Luczak, A. Transcranial direct current stimulation in stroke rehabilitation: A review of recent advancements. Stroke Res. Treat. 2013, 2013, 170256.

6. Ilić N, V.; Dubljanin-Raspopović, E.; Nedeljković, U.; Tomanović-Vujadinović, S.; Milanović, S.D.; Petronić-Marković, I.; Ilić, T.V. Effects of anodal tDCS and occupational therapy on fine motor skill deficits in patients with chronic stroke. Restor. Neurol. Neurosci. 2016, 34, 935-945. [CrossRef]

7. Elsner, B.; Kwakkel, G.; Kugler, J.; Mehrholz, J. Transcranial direct current stimulation (tDCS) for improving capacity in activities and arm function after stroke: A network meta-analysis of randomised controlled trials. J. Neuroeng. Rehabil. 2017, 14, 95. [CrossRef] 
8. Mills, E.J.; Bansback, N.; Ghement, I.; Thorlund, K.; Kelly, S.; Puhan, M.A.; Wright, J. Multiple treatment comparison metaanalyses: A step forward into complexity. Clin. Epidemiol 2011, 3, 193. [CrossRef] [PubMed]

9. Yozbatiran, N.; Der-Yeghiaian, L.; Cramer, S.C. A standardized approach to performing the action research arm test. Neurorehabil. Neural. Repair 2008, 22, 78-90. [CrossRef]

10. Gladstone, D.J.; Danells, C.J.; Black, S.E. The fugl-meyer assessment of motor recovery after stroke: A critical review of its measurement properties. Neurorehabil. Neural. Repair 2002, 16, 232-240. [CrossRef]

11. Moseley, A.M.; Herbert, R.D.; Sherrington, C.; Maher, C.G. Evidence for physiotherapy practice: A survey of the Physiotherapy Evidence Database (PEDro). Aust. J. Physiother. 2002, 48, 43-49. [CrossRef]

12. Foley, N.C.; Teasell, R.W.; Bhogal, S.K.; Speechley, M.R. Stroke rehabilitation evidence-based review: Methodology. Top. Stroke Rehabil. 2003, 10, 1-7. [CrossRef]

13. Cohen, J. Statistical Power Analysis for the Behavioral Sciences, 2nd ed.; Lawrence Erlbaum Associates: Mahwah, NJ, USA, 1988; pp. 147-150.

14. Rosenthal, R.; Rubin, D.B. A simple, general purpose display of magnitude of experimental effect. J. Educ. Psychol. 1982, 74, 166. [CrossRef]

15. Huedo-Medina, T.B.; Sánchez-Meca, J.; Marín-Martínez, F.; Botella, J. Assessing heterogeneity in meta-analysis: Q statistic or I ${ }^{2}$ Index? Psychol. Methods 2006, 11, 193. [CrossRef]

16. Borenstein, M.; Hedges, L.V.; Higgins, J.P.; Rothstein, H.R. Introduction to Meta-Analysis, 2nd ed.; John Wiley \& Sons Ltd: Hoboken, NJ, USA, 2021; pp. 59-94.

17. Simes, R.J. Confronting publication bias: A cohort design for meta-analysis. Stat. Med. 1987, 6, 11-29. [CrossRef]

18. Egger, M.; Davey Smith, G.; Schneider, M.; Minder, C. Bias in meta-analysis detected by a simple, graphical test. BMJ 1997, 315, 629-634. [CrossRef] [PubMed]

19. Alisar, D.C.; Ozen, S.; Sozay, S. Effects of bihemispheric transcranial direct current stimulation on upper extremity function in stroke patients: A randomized double-blind sham-controlled study. J. Stroke Cerebrovasc. Dis. 2019, 1, 104454. [CrossRef] [PubMed]

20. Allman, C.; Amadi, U.; Winkler, A.M.; Wilkins, L.; Filippini, N.; Kischka, U.; Stagg, C.J.; Johansen-Berg, H. Ipsilesional anodal $\mathrm{tDCS}$ enhances the functional benefits of rehabilitation in patients after stroke. Sci. Transl. Med. 2016, 8, 330re1. [CrossRef]

21. Beaulieu, L.D.; Blanchette, A.K.; Mercier, C.; Bernard-Larocque, V.; Milot, M.H. Efficacy, safety, and tolerability of bilateral transcranial direct current stimulation combined to a resistance training program in chronic stroke survivors: A double-blind, randomized, placebo-controlled pilot study. Restor. Neurol. Neurosci. 2018, 37, 333-346. [CrossRef]

22. Bornheim, S.; Croisier, J.L.; Maquet, P.; Kaux, J.F. Transcranial direct current stimulation associated with physical- therapy in acute stroke patients-a randomized, triple blind, sham-controlled study. Brain Stimul. 2020, 13, 329-336. [CrossRef] [PubMed]

23. Cho, H.S.; Cha, H. Effect of mirror therapy with tDCS on functional recovery of the upper extremity of stroke patients. J. Phys. Ther. Sci. 2015, 27, 1045-1047. [CrossRef]

24. Dehem, S.; Gilliaux, M.; Lejeune, T.; Delaunois, E.; Mbonda, P.; Vandermeeren, Y.; Detrembleur, C.; Stoquart, G. Effectiveness of a single session of dual-transcranial direct current stimulation in combination with upper limb robotic-assisted rehabilitation in chronic stroke patients: A randomized, double-blind, cross-over study. Int. J. Rehabil. Res. 2018, 41, 138-145. [CrossRef]

25. Figlewski, K.; Blicher, J.U.; Mortensen, J.; Severinsen, K.E.; Nielsen, J.F.; Andersen, H. Transcranial direct current stimulation potentiates improvements in functional ability in patients with chronic stroke receiving constraint-induced movement therapy. Stroke 2017, 48, 229-232. [CrossRef]

26. Hesse, S.; Waldner, A.; Mehrholz, J.; Tomelleri, C.; Pohl, M.; Werner, C. Combined transcranial direct current stimulation and robot-assisted arm training in subacute stroke patients: An exploratory, randomized multicenter trial. Neurorehabil. Neural. Repair 2011, 25, 838-846. [CrossRef]

27. Kim, D.Y.; Lim, J.Y.; Kang, E.K.; You, D.S.; Oh, M.K.; Oh, B.M.; Paik, N.J. Effect of transcranial direct current stimulation on motor recovery in patients with subacute stroke. Am. J. Phys. Med. Rehabil. 2010, 89, 879-886. [CrossRef]

28. Kim, S.H. Effects of dual transcranial direct current stimulation and modified constraint-induced movement therapy to improve upper-limb function after stroke: A double-blinded, pilot randomized controlled trial. J. Stroke Cerebrovasc. Dis. 2021, $30,105928$. [CrossRef]

29. Koh, C.L.; Lin, J.H.; Jeng, J.S.; Huang, S.L.; Hsieh, C. Effects of transcranial direct current stimulation with sensory modulation on stroke motor rehabilitation: A randomized controlled trial. Arch. Phys. Med. Rehabil. 2017, 98, 2477-2484. [CrossRef]

30. Lee, D.G.; Lee, D.Y. Effects of adjustment of transcranial direct current stimulation on motor function of the upper extremity in stroke patients. J. Phys. Ther. Sci. 2015, 27, 3511-3513. [CrossRef] [PubMed]

31. Lee, S.J.; Chun, M.H. Combination transcranial direct current stimulation and virtual reality therapy for upper extremity training in patients with subacute stroke. Arch. Phys. Med. Rehabil. 2014, 95, 431-438. [CrossRef] [PubMed]

32. Lindenberg, R.; Zhu, L.L.; Schlaug, G. Combined central and peripheral stimulation to facilitate motor recovery after stroke: The effect of number of sessions on outcome. Neurorehabil. Neural. Repair 2012, 26, 479-483. [CrossRef] [PubMed]

33. Lindenberg, R.; Renga, V.; Zhu, L.L.; Nair, D.; Schlaug, G.M.D.P. Bihemispheric brain stimulation facilitates motor recovery in chronic stroke patients. Neurology 2010, 75, 2176-2184. [CrossRef] 
34. Mazzoleni, S.; Tran, V.D.; Iardella, L.; Dario, P.; Posteraro, F. Randomized, sham-controlled trial based on transcranial direct current stimulation and wrist robot-assisted integrated treatment on subacute stroke patients: Intermediate results. In Proceedings of the 2017 International Conference on Rehabilitation Robotics, London, UK, 17-20 July 2017; IEEE: London, UK, 2017.

35. Menezes, I.S.; Cohen, L.G.; Mello, E.A.; Machado, A.G.; Peckham, P.H.; Anjos, S.M.; UGS, I.L.S.; Conti, J.; Plow, E.B.; Conforto, A.B. Combined brain and peripheral nerve stimulation in chronic stroke patients with moderate to severe motor impairment. Neuromodulation 2018, 21, 176-183. [CrossRef]

36. Mortensen, J.; Figlewski, K.; Andersen, H. Combined transcranial direct current stimulation and home-based occupational therapy for upper limb motor impairment following intracerebral hemorrhage: A double-blind randomized controlled trial. Disabil. Rehabil. 2016, 38, 637-643. [CrossRef] [PubMed]

37. Nair, D.G.; Renga, V.; Lindenberg, R.; Zhu, L.; Schlaug, G. Optimizing recovery potential through simultaneous occupational therapy and non-invasive brain-stimulation using tDCS. Restor. Neurol. Neurosci. 2011, 29, 411-420. [CrossRef] [PubMed]

38. Rabadi, M.H.; Aston, C.E. Effect of transcranial direct current stimulation on severely affected arm-hand motor function in patients after an acute ischemic stroke: A pilot randomized control trial. Am. J. Phys. Med. Rehabil. 2017, 96, S178-S184. [CrossRef]

39. Rocha, S.; Silva, E.; Foerster, Á.; Wiesiolek, C.; Chagas, A.P.; Machado, G.; Baltar, A.; Monte-Silva, K. The impact of transcranial direct current stimulation (tDCS) combined with modified constraint-induced movement therapy (mCIMT) on upper limb function in chronic stroke: A double-blind randomized controlled trial. Disabil. Rehabil. 2015, 38, 653-660. [CrossRef] [PubMed]

40. Sattler, V.; Acket, B.; Raposo, N.; Albucher, J.F.; Thalamas, C.; Loubinoux, I.; Chollet, F.; Simonetta-Moreau, M. Anodal tDCS combined with radial nerve stimulation promotes hand motor recovery in the acute phase after ischemic stroke. Neurorehabil. Neural. Repair 2015, 29, 743-754. [CrossRef]

41. Salazar, A.P.; Cimolin, V.; Schifino, G.P.; Rech, K.D.; Marchese, R.R.; Pagnussat, A. Bi-cephalic transcranial direct current stimulation combined with functional electrical stimulation for upper-limb stroke rehabilitation: A double-blind randomized controlled trial. Ann. Phys. Rehabil Med. 2019, 63, 4-11. [CrossRef]

42. Straudi, S.; Fregni, F.; Martinuzzi, C.; Pavarelliet, C.; Salvioli, S.; Basaglia, N. tDCS and robotics on upper limb stroke rehabilitation: Effect modification by stroke duration and type of stroke. Biomed. Res. Int. 2016, 2016, 5068127. [CrossRef]

43. Triccas, L.T.; Burridge, J.H.; Hughes, A.; Verheyden, G.; Desikan, M.; Rothwell, J. A double-blinded randomised controlled trial exploring the effect of anodal transcranial direct current stimulation and uni-lateral robot therapy for the impaired upper limb in sub-acute and chronic stroke. NeuroRehabilitation 2015, 37, 181-191. [CrossRef]

44. Viana, R.T.; Laurentino, G.E.C.; Souza, R.J.P.; Fonseca, J.B.; Filho, E.M.S.; Dias, S.N.; Teixeira-Salmela, L.F.; Monte-Silva, K.K. Effects of the addition of transcranial direct current stimulation to virtual reality therapy after stroke: A pilot randomized controlled trial. NeuroRehabilitation 2014, 34, 437-446. [CrossRef]

45. Yao, X.; Cui, L.; Wang, J.; Feng, W.; Bao, Y.; Xie, Q. Effects of transcranial direct current stimulation with virtual reality on upper limb function in patients with ischemic stroke: A randomized controlled trial. J. NeuroEng. Rehabil. 2020, 17, 1-8. [CrossRef] [PubMed]

46. Shaheiwola, N.; Zhang, B.; Jia, J.; Zhang, D. Using tDCS as an add-on treatment prior to FES therapy in improving upper limb function in severe chronic stroke patients: A randomized controlled study. Front. Hum. Neurosci. 2018, 9, 154. [CrossRef] [PubMed]

47. Brien, A.T.O.; Bertolucci, F.; Torrealba-Acosta, G.; Huerta, R.; Fregni, F.; Thibaut, A. Non-invasive brain stimulation for fine motor improvement after stroke: A meta-analysis. Eur. J. Neurol. 2018, 25, 1017-1026. [CrossRef]

48. Koganemaru, S.; Fukuyama, H.; Mima, T. Two is more than one: How to combine brain stimulation rehabilitative training for functional recovery? Front. Syst. Neurosci. 2015, 9, 154. [CrossRef] [PubMed]

49. Burdea, G.C. Virtual rehabilitation- benefits and challenges. Methods Inf Med. 2003, 42, 519-523.

50. Rothstein, H.R.; Sutton, A.J.; Borenstein, M. Publication Bias in Meta-Analysis: Prevention, Assessment and Adjustments; John Wiley \& Sons Ltd: Hoboken, NJ, USA, 2006; pp. 73-193. 